\title{
Research Projects and Failure Investigations Conducted Through a Commercial Materials Testing Laboratory
}

\author{
Jaret J. Frafjord ${ }^{1}$ \\ 1. IMR Test Labs, Portland, OR USA
}

This paper will describe work conducted with research staff and failure analysts.

There are advantages to using an accredited, commercial materials testing laboratory for research and failure investigations, even if there is little or no onsite expertise in the area of study. The expertise can come in the form of knowledge of equipment and how to best accommodate or design special test fixtures. These labs are fully capable of all mechanical, chemical and metallographic analysis to provide one-stop shopping for all testing needs. The personnel are fully trained and they use the equipment on a regular basis. The equipment is calibrated regularly to NIST standards. The labs are audited regularly and they perform in round robin proficiency tests to ensure accuracy.

One project involved conducting an extensive heat treat study to show how the properties changed through a variety of cooling rates. Two thermocouples were attached to the ends of the bar stock and heated in the same furnace. Each set of bar stock was removed and cooled at a different rate and the cooling rate monitored and plotted (Figure 1). Each bar was tested for hardness, microstructure, and tensile strength. Although the ultimate strength and elongation were not greatly affected, the yield strength dropped as the cooling rate increased. Differences in the microstructure is shown in Figure 2.

Another project involved testing a pin for a dam system in the Columbia River. The engineering team needed to test the strength of the metal pin at 38F to simulate the river temperature. A bath system was developed to allow the test specimen to soak in a bath of water and dry ice in the testing machine. The specimen soaked for 5 minutes prior to testing, and the tensile test was conducted while the test specimen was submerged in the water.

These and other projects will be discussed in detail, showing how the knowledge of equipment and test methods helped ensure proper and accurate results that could be traced to ASTM procedures and NIST standards. 


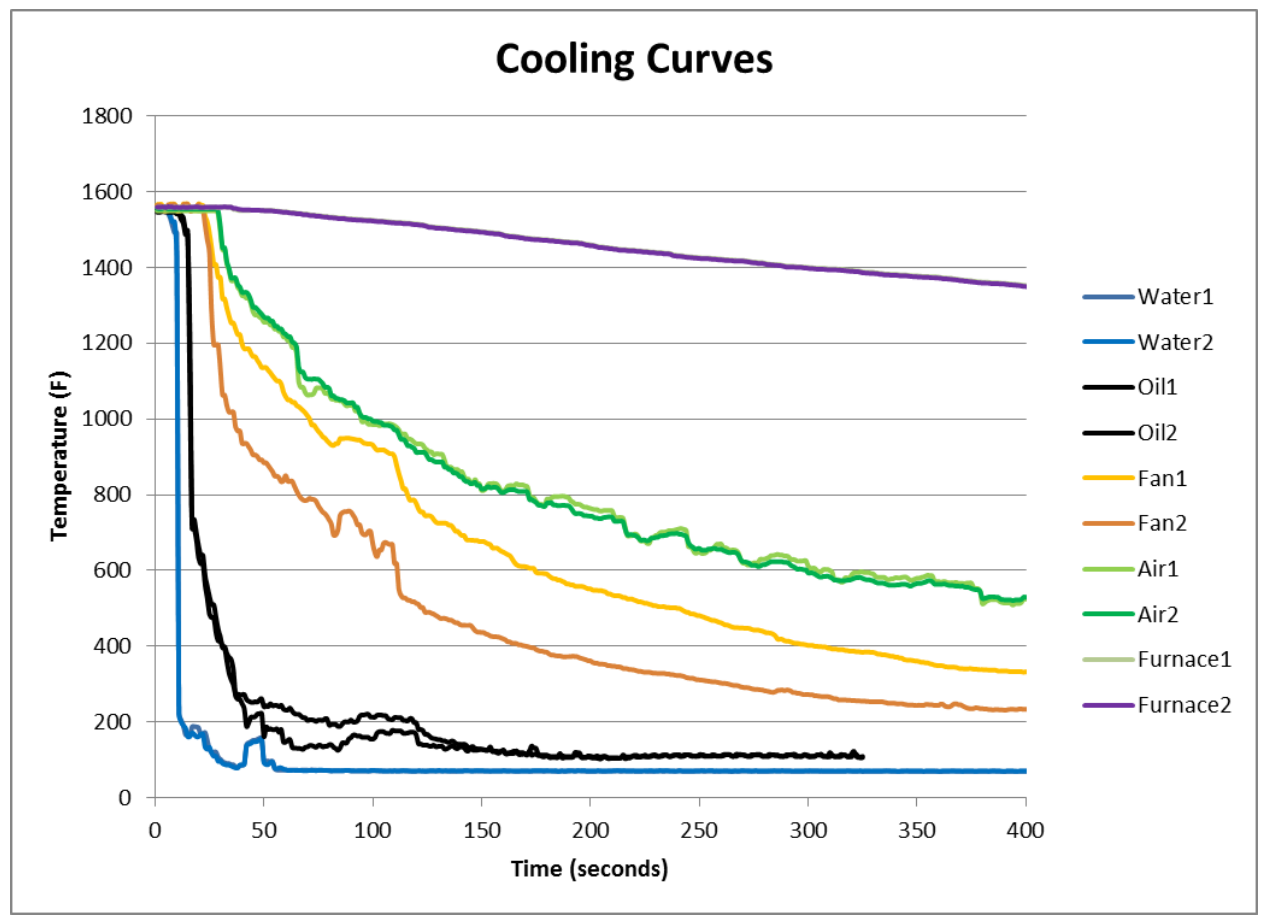

Figure 1. Cooling curves of a steel cooled by water, oil, fan, air, and furnace.
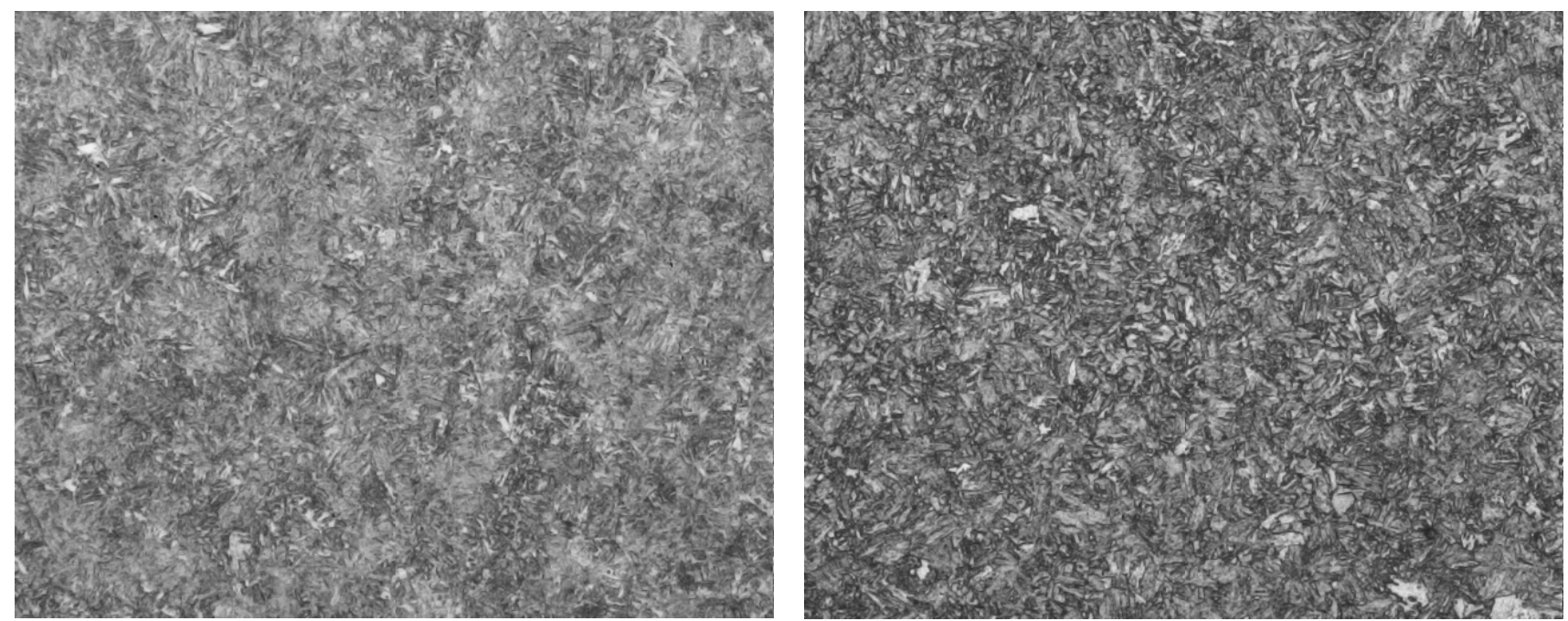

Figure 2. Micrographs of the steel in the water quenched condition (left) and the air cooled condition (right). 